\title{
Overview of Weapon Operational Suitability Test
}

\author{
Jieqiao Li a , Chenglong Nie, Lin Wang \\ School of Ordnance Engineering College, Shijiazhuang 050003, China. \\ a13591744046@163.com
}

\begin{abstract}
Elaborated the concept of the operational test and the operational suitability test, described the contact of them. Define the meaning and connotation of weapon operational suitability test. Against the problem of the weapons operational suitability test, starting from both the evolution of defined, suitability factors and applications, reviewed the research history of the operational suitability test at home and aboard, analyzed the characteristic and progress of research work, summarized the existing research results, according to the compare, indicated the shortage of the existing research. On this basis, researched on three aspects of the evaluation framework of the operational suitability, the operational suitability for tasks and the operational suitability types that have important reference significance for the relevant research staff.
\end{abstract}

Keywords: Weapon; Operational Test; Operational Suitability Test.

\section{Introduction}

In the 21 st century, with the rapid development of science and application, the level of modernization has continuous improved, which show features both systematic and complicated. Especially with the rapid development of information technology, joint operations under conditions of informationization will become the next major operational style. In the context of contemporary revolution in military affairs, construction of new operational forces and weapon, change the mode of generating operational, become the main development direction of the army. This requires not only weapon has good tactical and technical performance, but also it has sufficient capacity to adapt to the complex battlefield environment and weapon system [1] ability to fight. It is great significance to weapons adapt to battlefield and play operational effectiveness, under the conditions of close battleground. Therefore, in order to make weapons achieve "called for them to be able to fight", weapon tests must transform from the traditional performance test to the operational suitability test.

\section{Operational Test and Operational Suitability Test}

Weapons operational test [2] refers to comprehensive test and evaluation process, which makes by an independent agency based weapon confrontational training exercises, training and operational mission profile requirements to build similar battleground, realistic battlefield environment, using a variety of test methods and means to determine the operational suitability and the operational effectiveness of weapon. Weapon operational test mainly involves two aspects, both operational efficiency [3] and operational suitability. For weapon systems, weapon, consumers are most concerned about is the weapon of operational effectiveness and operational suitability. The operational suitability of weapons [4] has many factors, mainly related to the weapon itself of reliability, maintainability, availability, security, compatibility, interoperability, human factors, at the process of using, wartime usage, human security, resource security nature, effect and impact of the natural environment, as well as training documents and other factors. The operational suitability is an important prerequisite for weapon to accomplish a operational mission, achieve operational effectiveness. If the weaponry which operational suitability is non-compliance fielded, logistics support of weapon, implementation of operational tasks and even the safety of users would be seriously affected, even it would become a key factor affecting the outcome of war. Therefore, it has great significance to carry out a comprehensive study of the operational suitability of weapon, improve operational suitability of weapon system to ensure the effectiveness of operational weapon fielded forces before the mass production of fully tempered to ensure our weapon, especially 
high-tech weapon system to adapt to future battlefield environment, shortening the process weapon development, achieve scientific weapon acquisition decisions.

\section{The Research Status on Operational Suitability Test}

The present research shows that after a long period of practice and exploration, the US army has formed a complete theoretical system of operational applicability of weapons and weapon, while the research on the operational applicability of weapons and weapon is still at the initial stage, the theoretical system is not perfect, The practical applicability of specific weapon is less.

\subsection{The Development Course and Present Situation of Operational Suitability Tests Abroad 3.1.1 The Concept of Operational Suitability}

The operational suitability test started earlier in the US. In the 1960s, the US army put forward the concept of operational testing, the key objectives of the operational testing is testing operational effectiveness and operational suitability of weapons. Since 1980, operational suitability gradually attracted the attention of the US army, which reflected in terms of military aircraft initially. In the late 1980s, the US Department of Defense began a program to improve the operational suitability of weapons.

In the 1990s, The Operational Test and Evaluation guide [5] clearly defined the operational adaptability. The US army considered that operational suitability is the to which can be satisfactorily placed in field use, with consideration given to availability, compatibility, transportability, interoperability, reliability, wartime usage rates, maintainability, safety, human factors, manpower supportability, logistical supportability, natural environmental effects and impacts, documentation and training requirements. In addition, The Requirements Generation System defines operational suitability as The degree of weapon system which deployed, used and maintained while meeting the performance parameters of the system and the user performance requirements. is satisfactorily in the mission area.

\subsubsection{Operational Suitability Factors and Application}

Two text precept have been proposed of the Operational Suitability Test and Evaluation guide. One is the "system-oriented suitability" operational test and evaluation, which determines whether the acceptable minimum performance requirements specified in the Operational Requirements Document have been met; the other is "the applicability of a mission-oriented task "Operational test and evaluation, this program is based on the applicability of the matter, to determine whether the ability of the weapon system to meet mission requirements. In 2010, the US Air Force Operational Experiment and Evaluation Center (AFOTEC) issued a "Operational Suitability Test and Appraisal Guide" which reaffirmed that operational suitability is an important indicator of operational testing, and that operational applicability represents the use of weapons in operational use, Which is mainly affected by the reliability, availability, compatibility, satisfactorily, transportability, interoperability, human factors, wartime utilization, supportability, natural environmental effects and the effectiveness of the weapon system, documents and training requirements and so on. The Guide clearly define these factors, and describe the aspects, importance, and subordinate indicators of these factors, and provide guidance for further testing and identification.

The US Army have carried out the operational suitability identification and practical application, in order to improve the suitability of weapons. For example, an independent experimental group of the US Navy's Air Test and Identification Squadron conducted an operational suitability test of a Air-to-ground Attack-Extended Range Response (SLAM-ER) missile at Naval Air Test Site in Lake China, California, in June 1998, And commander, operational suitability test and identification force submitted the OPEVAL report, assessment the SLAM-ER can be suitable for operation; In March 2000, the US Army completed the operational suitability test of the Ram Block 1 ship self-defense system at the Atlantic missile test range. In 2008, the US Department of Defense Operational Test and Evaluation Bureau (DOT \& E) submitted operational suitability report Of the "Global Hawk" Block 10 UAV, which pointed out that the first batch of deployed UAV can't meet the operational suitability 
requirements in the implementation of image intelligence tasks. For a long time, the US Army incorporated the operational suitability test into the whole process of the weapon development and production. From the view of organizational, the US Army had the independent and specialized agencies which set up by the Army, Guaranteed strict organization and implementation, formed a set of sound management system and theoretical methods through years of accumulation and innovation. From the view of legal system, the US Army built a clear and perfect level of the legal system with the level of "legal-regulations-rules", which mad fully the suitability test of the weapon following the legal, and then cooperated closely with research institutes, trained a large number of related persons, built a solid talent [6]. More importantly, the US Army could implement the operational tests rigorously, and build the environment realistically. For example, Army weapons which had through environmental simulated tests should been sent to test at the desert, cold regions, thermal zones environment test centers. The results of test and identification directly related the development of the weapon.

\subsection{The Development Course and Present Situation of Operational Suitability Tests Inland 3.2.1 The Concept of Operational Suitability}

China's operational suitability research starts later than abroad, remains at the stage of development, there will inevitably be some shortcomings. At present, the Army has begun to attach importance to the study of the operational suitability, and has achieved some results. Some scholars of the domestic made some make definitions of the operational suitability. Wu Xiaoyue, Liu Qi [4] defined the operational suitability as that "weapons which used in the process can be maintained to the extent of available, that is to say, The extent of the person who complete the provisions task in the field at the condition of perfect safeguards programs and resources, which is defined as factors it has considered such as availability, compatibility, transportability, interoperability, reliability, wartime use, maintainability, security, logistical support, natural environment, training requirements, the weapon used and kept the level of satisfaction at the battlefield." Zeng Tianxiang [7] believe that operational suitability is a characteristic of performance to describe the modern military aircraft in the combat environment, it considers the reliability, maintenance, availability, testing, security and other elements, it is the important factors which impact military aircraft combat capability, but also the key use characteristics of testing and evaluating. Good operational suitability is one of the main objectives to be achieved in the development of modern military aircraft.

There are also some experts and scholars with different definition or analysis of the operational suitability for different types of weapon. Such as, Wen Cheng, YI Xiaoshan [8] think that operational suitability mainly reflects the degree of weapon meeting the actual requirements, for the definition of availability, reliability, capability, human error and environmental suitability, and put forward the measure degree of operational use in the " The Operational Suitability Model of Command and Control System" (2008). Wang Ya [9] defined operational suitability refers to the degree of weapon used in the combat environment, comprehensive considering reliability, availability, maintainability and other factors, in the "The Operational Suitability Analysis and Evaluation Method of Military Integrated Electronic Information System " (2010). Ma Lingling [10] thinks the range of the operational suitability test and evaluation including weapon, operators/maintainers and logistical support structure in the "The Operational suitability Test and Evaluation of the Correspondence Combat Weapons".

From the above definition, we can see that the operational suitability of the weapons represents a measure to meet the operational use of combat, but that has different factors of different weapons. Combining the above research results, the following definition can be derived that:"operational suitability of weapon refers to the process to achieve the degree of customer satisfaction with reliability, maintainability, availability, security, compatibility, interoperability, human factors, wartime use, manpower support, resource support, natural environmental effects and impacts, documentation and training. 


\subsubsection{Operational Suitability Factors and Application}

There are many factors influencing the operational suitability of weapons, and Cao has studied the characteristics of each factor, and divided the main factors into four categories, such as the characteristics that need to be put into operation, the characteristics that can perform well in the execution of tasks, the characteristics of easy operation and use. Wang Zhimeng [11] divided weapon operational suitability test into test evaluation and comprehensive evaluation two levels to analyze. So far, although the relevant experimental ideas and experimental content has been reflected in some experimental work, but our military does not explicitly put forward the operational suitability test of weapons. From the acquisition cycle of weapons, the design test includes depot test and using test, the depot test mainly tests weapon performance and general performance, the using test of military tests weapon performance and suitability. Since the beginning of the new century, our army has accelerated the pace of development of weapons, and successively issued a series of standards and regulations for the development, standardized the development, testing and finalization; the weapon and research and management departments of the armed forces have attached great importance to weapon combat tests, have started to study and explore the establishment of the weapon combat test center, weapons and weapon development and finalization of the work gradually embarked on a scientific and standardized track. However, the aspect of operational suitability test also have a certain gap, for the following points:

a) Due to the long-term development of peace, lacking real data of the practical combat operational suitability, and the understanding is not deep enough.

b) The test focuses on the single performance, lacks combined suitability test and the suitability test of the cluster weapon interaction.

c) The battlefield environment is not realistic enough, lacking tactical environment and confrontation.

\section{Weapons Operational Suitability Analysis and Evaluation}

\subsection{The Evaluation Framework of Operational Suitability}

The two pillars of military capability are combat readiness and sustained combat capability. Combat readiness refers to the ability to deploy and use weapons, and to play a role. Continued combat capability refers to the ability of weapons to carry out combat tasks according to the necessary intensity and duration to achieve military objectives, which involves various factors such as the type, quantity, weapon system, consumables and weapon level. From Fig 1, the key issues relating to applicability of the bottom layer must be addressed in order for the weaponry to be satisfactorily put into use on the battlefield, to achieve good operational readiness and sustained operational capability.

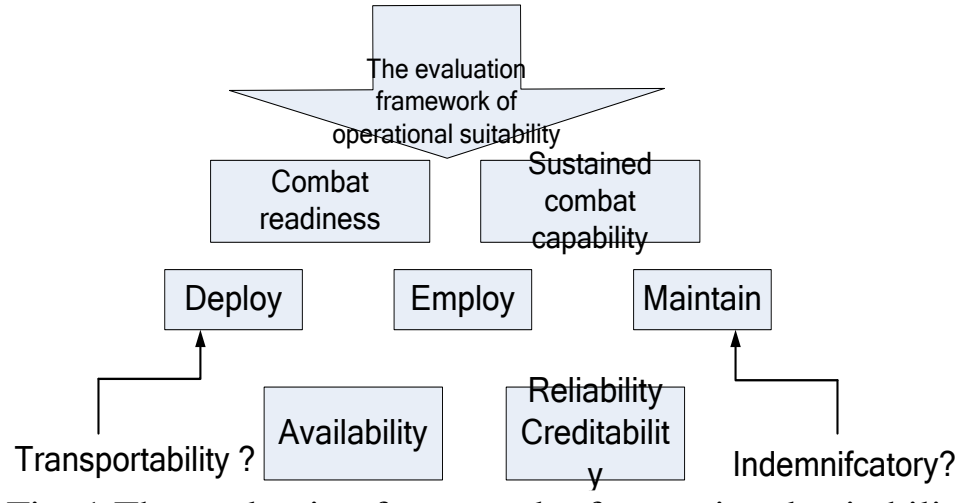

Fig. 1 The evaluation framework of operational suitability

\subsection{Analysis on the Operational Suitability for Weapon at Combat Task}

The operational suitability for task-oriented weapons is to judge the suitability from the perspective of the battlefield, and judge whether the weapon meets the task demand according to the suitability. And that researching through the task-oriented, that can assess the influence of the suitability to the operational tasks and the various sub-tasks. 
From the perspective of the task, we can find that, the target of the suitability is different in different stages of the task. Prior to carrying out the mission, the goal is to plan and provide adequate logistical support for the systems that will be put into the intended operational environment so that they can continue to function for the required time. During mission execution, suitability is concerned with keeping the system in a state of warfare through maintenance, spare parts, and other similar methods. After the task is completed, goal is changed to make the system have the ability to repeat the task.

According to the stage of the task, weapon operational suitability test can be divided into three stages. Firstly, pre-task suitability testing. secondly, suitability testing during tasks. what's more, post-task suitability test. According to the task requirements, the weapon were tested with the maneuver deployment capability, ready capacity, wartime ability to perform tasks, continuous combat capability at battlefield [12].

\subsection{Analysis of Weapon Operational Suitability}

From the point of view of weapon capability, operational test is mainly to evaluate the combat readiness and continuous combat capability of the weapon in the suitability. From the point of view of weapon performance, it is mainly to evaluate the availability, operational availability, supportability, and other indicators [13]. Operational suitability test can be divided into three parts, operational suitability test of environment, operational suitability test of employment and operational suitability test of support.

a) Operational suitability test of environment

Weapons operational suitability of environment refers to the weapon ability to adapt to environmental conditions and work effectively. Operational environment conditions here include the battlefield natural environment, the joint fire environment, battlefield electromagnetic environment and battlefield transportation environment four aspects.

b) Operational suitability test of employment

The weapon operational suitability of employment refers to the convenience degree of weapons in employment. Whether weapon is safe, reliable, with good human factors, which are three main factors.

c) Operational suitability test of support

The weapons operational support refers to the ability, in order to maintain combat regeneration and continuous combat capability, weapons to be timely and effective repair, maintenance and ammunition supplies. Therefore, the weapon operational suitability of support including the suitability of operational support and maintenance tests, operational support test and operational support resources test.

Operational suitability test

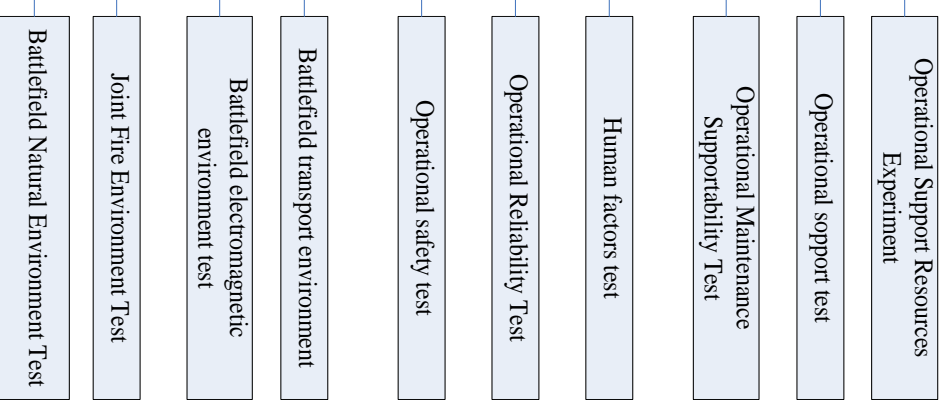

Fig 2 Analysis of Weapon Operational Suitability 


\section{Conclusion}

This paper compares the applicability of our military and the US military, and illustrates the weaknesses of our military by comparing the development of the suitability test of US and Chinese military weapon combat. The main content of the operational suitability test of the weapon is studied preliminarily. It is more scientific and effective to evaluate the operational applicability of the weapon, and it has a certain effect on the development of the combat applicability test. In order to improve the weapon suitability and adaptability the future battlefield environment is of great significance.

\section{References}

[1] Yan Xuefei, Li Xinming, Liu Dong. Technologies for Evaluation of Weapon SOS and Status. Fire Control \& Command Control. Vol. 44(2016) No. 1, p. 7-10.

[2] Wang Kai, Zhao Dinghai, Yan Yaodong, et al. The Operational Suitability Test of Weapons. National Defense Industry Press, 2012.

[3] Ma Qingyue: Research on Comprehensive Evaluation Techniques for Weaponsystem of Systems' Operational Effectiveness (Master, Harbin Institute of Technology, China 2015)

[4] Wu Xiaoyue, Liu Qi. Test and Evaluation of Weapons. National Defense Industry Press, 2008.

[5] Maj Brian E. Kennedy, Lt Gen Howard. W. Leaf. Operational Test and Evaluation, AD A331257.

[6] Luo Gang, Kang Huali, Lu Wei. Consideration for Some Issues of Equipment Operational Test by PLA. Jourmal of Equipment Academy. Vol. 25(2014) No. 3, p. 103-106.

[7] Cao Tianxiang, Wei Zishang, Zhang Baozhen. The technology of Improving the Operational Suitability of Military Aircraft. Aerotechnics Flight International. Vol. 1(1995) p. 15-18.

[8] Wen Cheng, Yi Xiaoshan. Operational Suitability Modelling Establishment for Command System. Ordnance Industy Automation. Vol. 12(2008) No. 27, p. 61-63.

[9] Wang Ya. Analysis and Assessment of Operational Suitability of Military Integrated Information Systems. Fire Control \& Command Control. Vol.8 (2010) No. 35, p. 75-79.

[10] Ma Lingling, Feng Weiyong, Guo Quan. Operational Suitability Test and Evaluation Applied to Equipments of Communications Electronic Warfare. Naval Facility. Vol.7 (2010) p.33-34.

[11] Wang Zhimeng, Li Gang, Wang Kunming. Research on Operational Test Evaluation of Army Equipment. The Theory and Practice of Army Operational Test.

[12] Dong Jian, Hu Haibo, Chen Guiming, et.al. Study of the Evaluation Index System of Task Requirement-oriented Weapon System Operational Suitability. Value Engineering. Vol.1(2013) No. p. 312-313.

[13] Ke Hongfa, Du Hongmei, Zhao Jiguang, et.al. Test and Evaluation on Adaptability of Electronic Equipment to Complex Electromagnetic Environment. National Defense Industry Press, 2015. 